\title{
Financial Crises and Labor Market Turbulence
}

\author{
Sangeeta Pratap \\ Hunter College \& Graduate Center \\ City University of New York \\ Erwan Quintin* \\ Federal Reserve Bank of Dallas
}

February 14, 2009

Preliminary- Do not quote

\begin{abstract}
Financial crises cause significant reallocation of labor across sectors and occupations. This results in transitory losses in the quality of labor as specific human capital is destroyed and workers devote time to learning new skills, among other possible transition costs. In other words, crises are periods of high turbulence in the sense of Ljunqvist and Sargent (1998). In this paper, we provide strong evidence that these losses were substantial in the case of Mexico's 1994-95 crisis. Workers that changed occupations or sectors during the crisis lost more than $10 \%$ in wages, compared to those who did not. We show that these losses in productivity can account for a significant part of the drop in conventionally-measured TFP that took place during the crisis.
\end{abstract}

Keywords: Financial crises; labor market turbulence, total factor productivity; output fluctuations

JEL classification: E32; F41; J24

\footnotetext{
${ }^{*}$ E-mail: sangeeta.pratap@hunter.cuny.edu, erwan.quintin@dal.frb.org. We would like to thank Felipe Meza and Diego Restuccia for many helpful discussions. We are grateful to Eric Verhoogen for help with the data and to Nate Wright for valuable research assistance. The views expressed in this paper are not necessarily those of the Federal Reserve Bank of Dallas or the Federal Reserve System.
} 


\section{Introduction}

Financial crises cause real output to collapse. They also cause massive changes in relative prices and therefore, over time, a significant reallocation of resources. Many workers are constrained to change jobs, occupations, even sectors, causing losses in specific human capital. In this paper, we provide direct evidence that these losses were significant during Mexico's tequila crisis. We also argue that this fact could help account for the well documented observation that output typically falls much more during crisis than what standard measures of labor and capital use would lead one to expect ${ }^{1}$.

We begin by showing that the frequency of involuntary job separations and the associated displacement costs both rise during crises using data from Mexico's Encuesta Nacional de Empleo Urbano, a broad urban household survey. We find that during the Tequila crisis, workers who changed sectors and/or occupations experienced a significantly larger fall in earnings than observably similar workers who stayed put in the same sector or occupation. We argue that this pattern is robust to a host of econometric considerations. In particular, we employ semi-parametric methods to make sure that our results do not depend on a particular specification of earning functions.

This fact has important implications for the fast-growing literature on the collapse of conventionally-measured TFP that characterizes most financial crises. A natural explanation for this collapse is that effective input use deviates significantly from measured input use during periods of financial turmoil. Several studies (Gertler et al., 2007, Meza and Quintin, 2007, Otsu, 2006) have argued that crises create strong incentives for firms to postpone the use of labor and capital services until conditions improve. They find that factor utilization can account for a significant part of the drop of TFP that occurs during crises. ${ }^{2}$

\footnotetext{
${ }^{1}$ see Meza and Quintin, 2007, for a review

${ }^{2}$ Several studies investigate the real impact of financial crises. Pratap and Urrutia (2008) assume that firms face a cash in advance constraint on the purchase of intermediate goods and show that under that assumption, a rise in interest rates leads to an increase in the misallocation of resources and hence a fall in TFP. Burnside, Eichenbaum and Rebelo (2001), Corsetti, Pesenti and Roubini (1999) and Lahiri and Vegh (2007) provide qualitative explanations for the contraction of output. Cavallo, Kisselev, Perri and Roubini (2004) show that large falls in output are possible after crises in sticky-price models with a margin constraint.
} 
The findings we present in this paper suggest another reason why effective and measured input use differ during crises: losses in the average quality of labor caused by worker reallocation between sectors and occupations. ${ }^{3}$ We describe a model that formalizes the theoretical link between these losses and the behavior of conventionally-measured TFP. Specifically, we consider an environment where firms combine the human capital workers supply with physical capital to produce a homogeneous good. Workers differ in terms of the human capital they are able to deliver in each period. We show that aggregate output in this environment is a simple function of aggregate capital, aggregate employment, and the average productivity of workers, establishing a tight theoretical link between this last argument and TFP as it is conventionally defined.

The next section estimates the movements in labor markets in Mexico in the decade of the financial crisis and computes the movements in TFP in this period. We also document that workers who move between sectors and occupations during the crisis suffer a substantial wage loss, compared to similar individuals who do not move. Section 3 presents the model and calibrates it to the Mexican economy. We show that a drop in labor quality compatible with the observed wage losses is sufficient to account for the drop in output and TFP. Calibrating the persistence of the productivity loss to match the persistence of earnings in the data, we find that the model can also account for the slow recovery of TFP after the crisis. Section 4 presents our numerical simulations and Section 5 concludes.

Similarly, Cook and Devereux (2005) simulate recent crises in Malaysia, South Korea and Thailand and show that output can drop sharply following shocks to a country's risk premium. All these papers assume that TFP is constant. Mendoza (2002) and Mendoza (2008) show that a flexible-price model with a liquidity constraint can lead to sudden stops of capital flows and large output falls. He allows for TFP fluctuations, but only of average business cycle size: the standard deviation of TFP fluctuations coincides with that of output. Chari, Kehoe and McGrattan (2005) show that sudden stops of capital flows induce an output increase, not a fall, in a standard neoclassical model with standard preferences.

${ }^{3}$ Kambourov and Manovskii (2007) document that returns to occupational tenure in the US are quite large. We find that moving occupations and/or sectors is accompanied by significant wage losses during financial crises. 


\section{The consequences of financial turmoil}

This section documents the fact that the pace of worker movements rises substantially during financial crises. We also show that these movements are associated with significant wage losses in this period. Simultaneouls,y there is al large fall in TFP.

\subsection{Worker reallocation}

Financial crises create perfect conditions for an acceleration of resource reallocation, as affected economies contend with a variety of shocks. Most obviously, the domestic cost of credit rises sharply, rendering finance-intensive activities less profitable. Firms that rely on outside sources of finance are forced to shrink to pay off increased debt liabilities, or in some cases, shut down. Second, the ratio of export prices to import prices (the terms of trade) usually rises and the real exchange rate deteriorates, leading over time to a reallocation of production toward export and away from goods and services produced for domestic use. Third, crises nations often undergo deep fiscal shocks as a part of the government's effort to boost tax revenues. Among other consequences, hikes in tax rates create incentives for workers to leave the formal, tax paying sector.

Figure 1 documents these shocks in the case of Mexico's Tequila crisis. The quarterly interest rate on dollar-denominated debt more than doubled during the first two quarters of 1995, while the real exchange rate fell by more than $55 \%$. In an effort to reduce the budget deficit, Mexico also increased the rate of consumption taxation noticeably in the first quarter of 1995, as well as the official price of various energy products.

This myriad of shocks makes worker movements across employers, occupations and sectors necessary. To gauge the intensity and the consequences of these movements, we use detailed micro data from a nationally representative annual employment and remuneration survey, the Encuesta Nacional de Empleo Urbano (ENEU). This is a rotating panel with 5 quarters of information for each worker, which includes individual information such as age, gender, education, marital status and occupation and job characteristics like firm size, formality and 
Figure 1: Shocks during Mexico's Tequila crisis
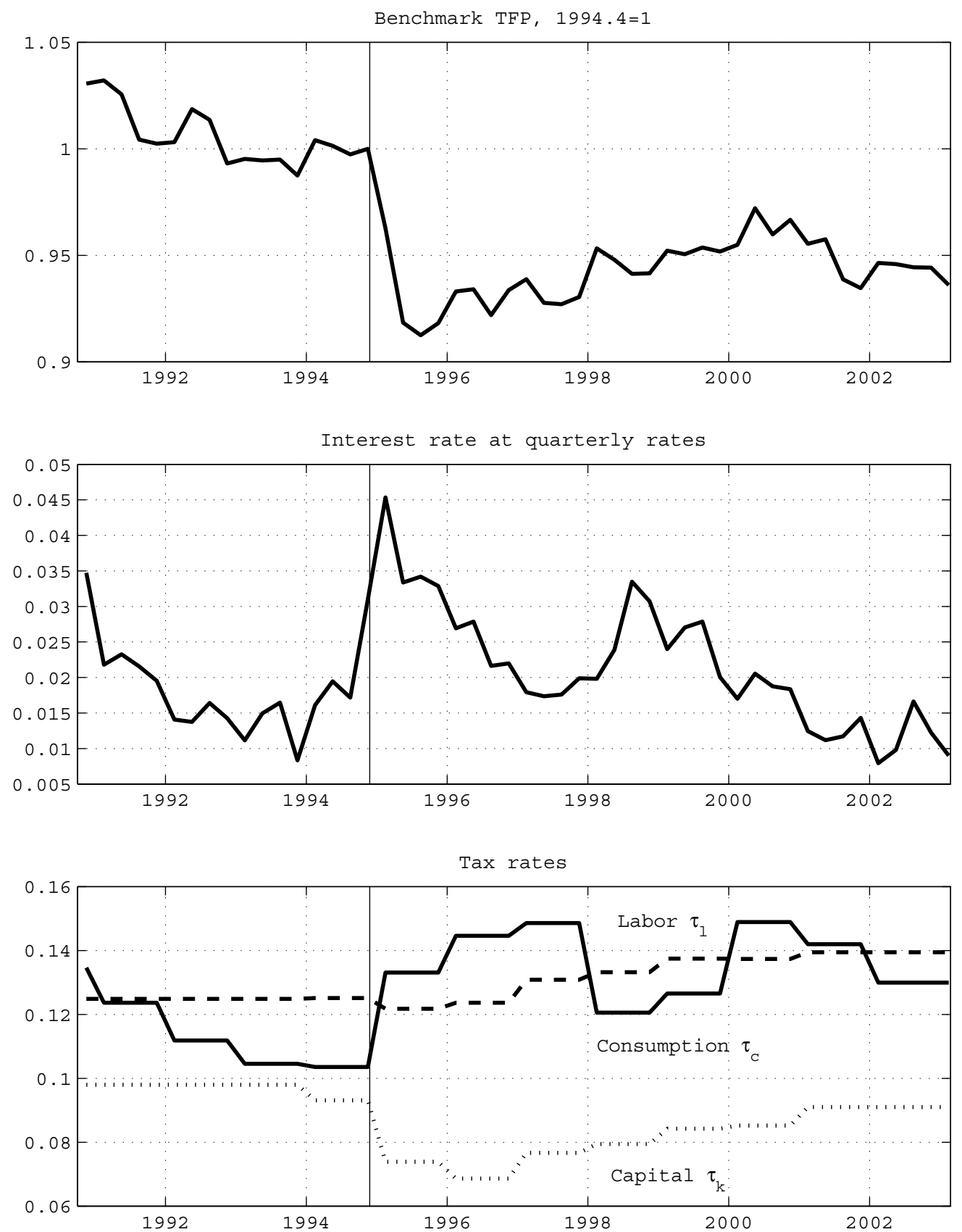

Source: Meza and Quintin, 2007 
sector of activity. Our sample consists of all employed individuals between the age of 16 and 65 for the period 1988 to 1999 with a total of about 3 million observations.

The survey reveals, first, that the country's open unemployment rate doubled to over 7 percent during the first two quarters of 1995. The impact of this jump on overall employment was only partially mitigated by an increase in the rate of labor participation, and overall hours worked declined.

In addition, the fraction of involuntary separations increased significantly in 1995. The household survey contains a question which one can use to break down recent separations according to whether they were initiated by the employee or the employer. As figure 2 shows, the ratio of terminations initiated by the employer to overall terminations rises by almost 20 percent during the crisis.

Figure 2: Fraction of involuntary separations

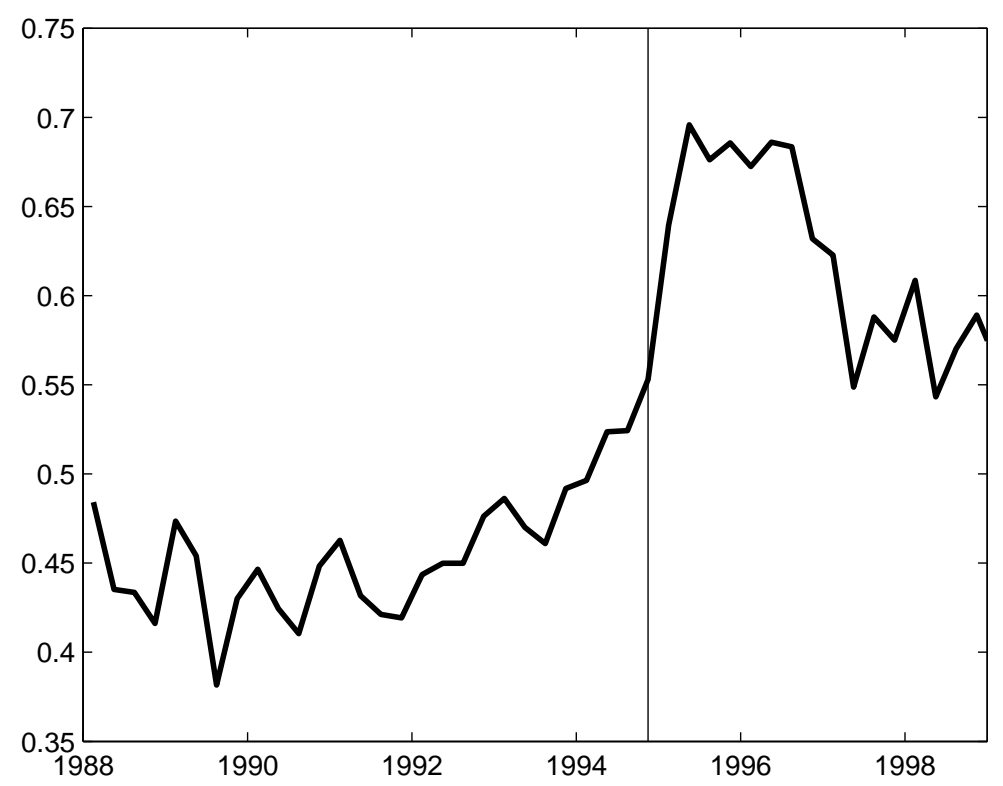

Source: Encuesta Nacional de Empleo Urbano, INEGI.

As our TFP computations show, the fall in output was much larger than the fall in 
employment. Inactivity spells, whether voluntary or involuntary, are therefore only part of the reallocation story. Many workers who remain employed during the crisis report significant changes in their work conditions. For example, the fraction of self-employed workers and the fraction of workers who work for an establishment with 5 employees of fewer both increased markedly in 1995 (see figure 3.) As is often the case in emerging economies, the untaxed, unregulated sector accounts for a large fraction of production and employment in Mexico. The informal sector includes all establishments and self-employed individuals that do not comply with government regulations such as labor laws and the tax code. Informal employees typically fail to receive government-mandated benefits and may be paid below the minimum wage. The last panel of figure 3 shows that the fraction of workers who fail to receive the benefits mandated by labor laws did in fact spike up in 1995.

Finally, the household survey also reveals that many of these worker transitions involved occupational and industry changes. Table 1 shows the fraction of workers that change sector and occupation between the last quarter of each year and the preceding year. Sector and occupation are defined at the 4 digit level. ${ }^{4}$ The fraction of workers that changed sectors and occupations increased noticeably between 1994 and 1995, as did the fraction of workers that changed sectors only. Only $34 \%$ of workers did not change either sector or occupation, down from $41 \%$ in the previous year. ${ }^{5}$ The reduction in the movement across sectors and occupations from 1995 onwards reflects that the changes engendered by the crisis were relatively long lasting, and were not reversed within a year or so of the crisis.

Another measure of large movements in the labor market is the change in the distribution of labor across occupations and sectors. Although these changes measure net, rather than gross labor movements, it is still instructive to look at them to see how labor is redistributed across sectors and occupations. Figure 4 shows the Kolmogorov-Smirnov Statistic for the two

\footnotetext{
${ }^{4}$ The occupational classification changed in the second quarter of 1992, so this statistic cannot be computed for that year.

${ }^{5}$ The drop in individuals that change occupation without changing sectors probably reflects a decline in upward mobility in this period. In other words, promotions that involve a change in occupation from worker to manager are probably less frequent in periods of crisis.
} 
Figure 3: Worker movements during Mexico's Tequila crisis
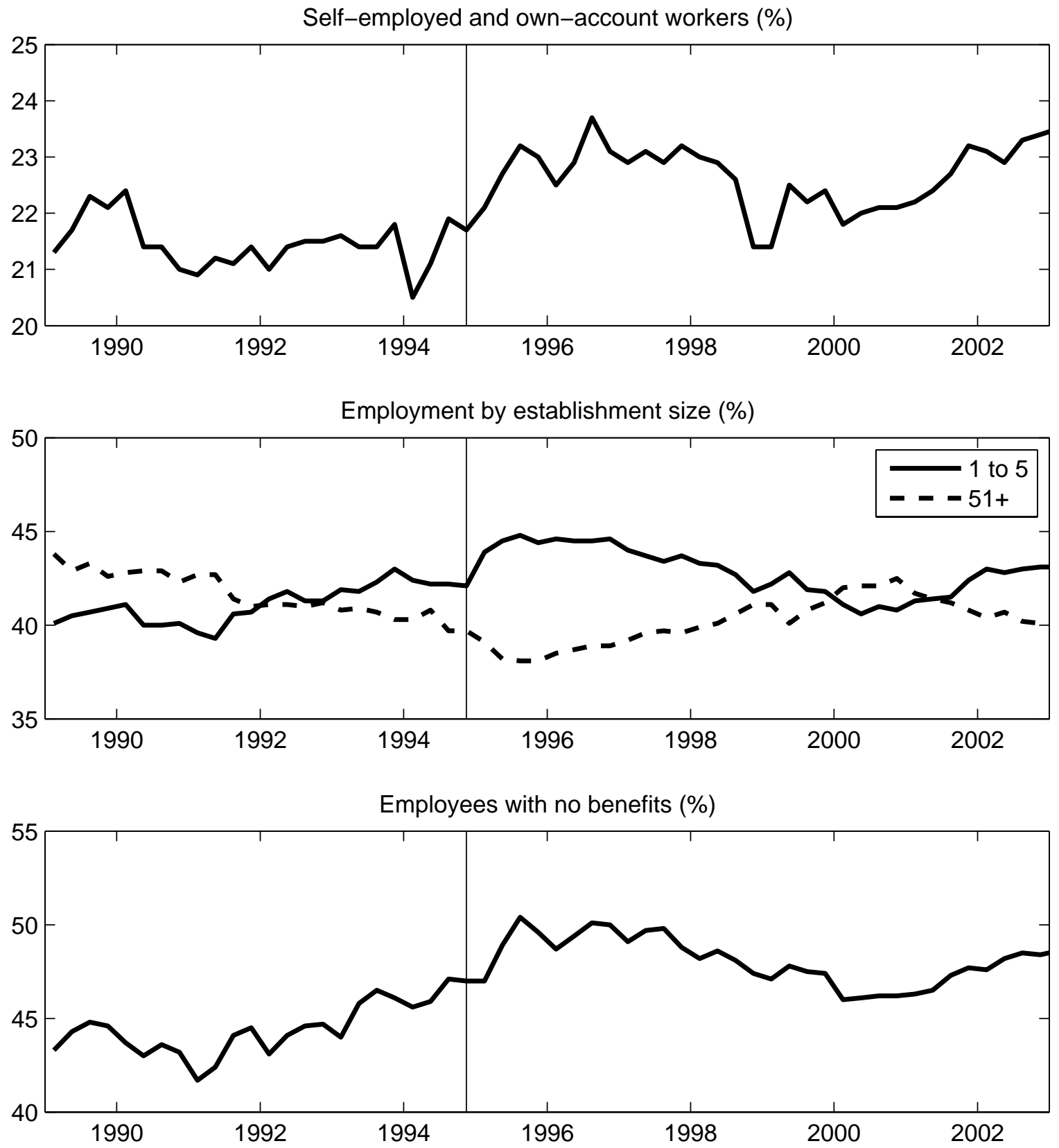

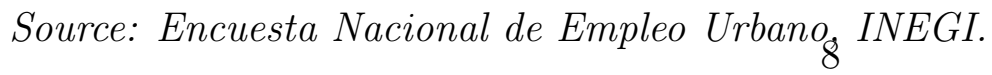


Table 1: Movements across sectors and occupations

\begin{tabular}{|c|c|c|c|c|}
\hline & $\begin{array}{l}\text { Fraction of wo } \\
\text { change sector } \\
\text { change occ. }\end{array}$ & $\begin{array}{l}\text { kers that } \\
\text { change sector } \\
\text { only }\end{array}$ & $\begin{array}{l}\text { change occ } \\
\text { only }\end{array}$ & no change \\
\hline 1988.4 to 1989.4 & 0.30 & 0.12 & 0.23 & 0.36 \\
\hline 1989.4 to 1990.4 & 0.27 & 0.13 & 0.24 & 0.36 \\
\hline 1990.4 to 1991.4 & 0.27 & 0.13 & 0.23 & 0.37 \\
\hline 1991.4 to 1992.4 & Not Available & & & \\
\hline 1992.4 to 1993.4 & 0.26 & 0.14 & 0.21 & 0.40 \\
\hline 1993.4 to 1994.4 & 0.24 & 0.13 & 0.22 & 0.41 \\
\hline 1994.4 to 1995.4 & 0.28 & 0.20 & 0.18 & 0.34 \\
\hline 1995.4 to 1996.4 & 0.23 & 0.12 & 0.22 & 0.43 \\
\hline 1996.4 to 1997.4 & 0.23 & 0.12 & 0.22 & 0.43 \\
\hline 1997.4 to 1998.4 & 0.24 & 0.10 & 0.22 & 0.43 \\
\hline 1998.4 to 1999.4 & 0.25 & 0.11 & 0.23 & 0.42 \\
\hline
\end{tabular}

sample to test for changes in the distribution of labor between sectors and occupations from quarter to quarter. This statistic is computed as

$$
\sqrt{\frac{n n^{\prime}}{n+n^{\prime}}} D_{n, n^{\prime}}
$$

where

$$
D_{n, n^{\prime}}=\sup _{x}\left|F_{n}(x)-F_{n^{\prime}}(x)\right|
$$

where $F_{m}(x)$ is an empirical cdf defined as

$$
\begin{aligned}
F_{m}(x) & =\frac{1}{m} \sum_{i=1}^{m} I_{X_{i} \leq x} \\
I_{X_{i} \leq x} & =1 \text { if } X_{i} \leq x \\
& =0 \text { otherwise }
\end{aligned}
$$

This statistic rose sharply in 1995, reflecting significant changes in the occupational and sectoral composition of the work force. 
Figure 4: Kolmogorov-Smirnov test statistic for distributional change

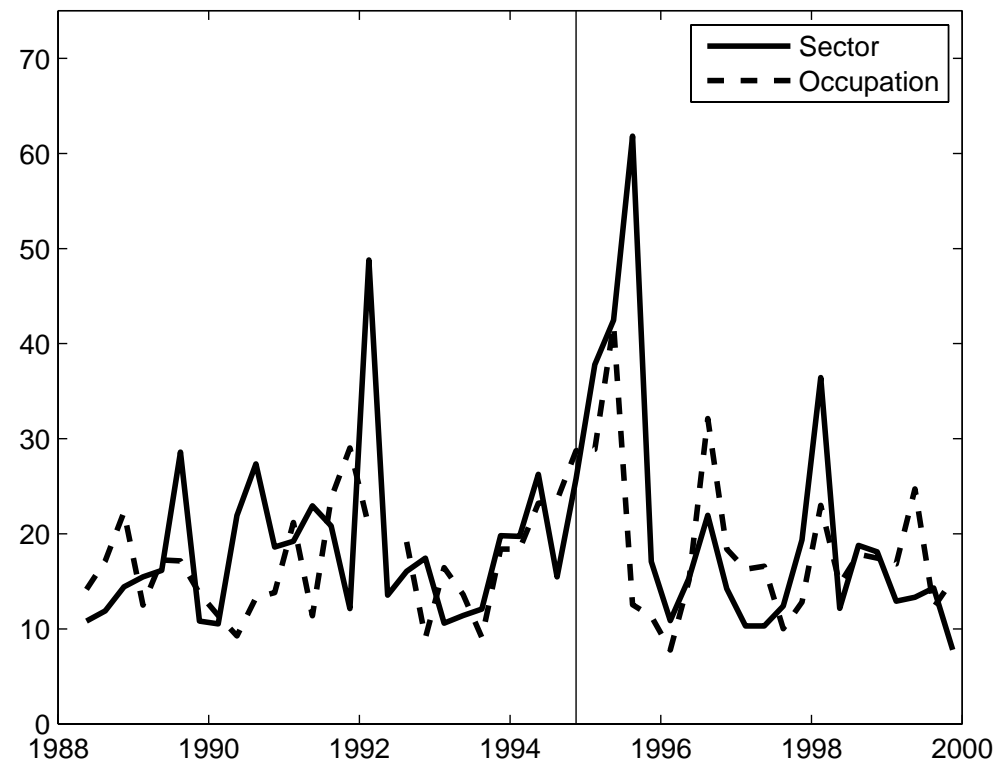

Source: Encuesta Nacional de Empleo Urbano, INEGI, authors' calculations.

To sum up, the 1995 crisis appears to have been accompanied by significant movements in labor markets. This in itself is not indicative of a fall in productivity and can be a sign of a well functioning labor marketin normal times. The next subsection shows that this is true in the data in non-crisis years. However, in 1994-1996, movements of labor were associated with significant wage losses for the movers.

\subsection{Labor market reallocation and earnings}

Average real wages fell by over $18 \%$ during the crisis and, despite increases in recent years, have yet to recover to pre-crisis levels. We will now present evidence that a large part of this fall was due to wage losses incurred by individuals who moved sector or occupation in this period. 


\subsubsection{Parametric results}

Table 2 shows the effect of occupational and sectoral changes on real wages. The variables Same Occupation and Same Sector take the value 1 if the individual does not change occupation and sector respectively in that quarter. The Crisis Dummy is set to 1 for all quarters of 1995 and 1996. Formal sector and self employment dummies are also included.

Table 2: Parametric results

\begin{tabular}{l|ll|ll}
\hline \hline Dependent Variable: & \multicolumn{2}{|l|}{ Random Effects } & \multicolumn{2}{l}{ Fixed Effects } \\
log real wage & Coeff. & Std Error & Coeff. & Std. Error \\
\hline Constant & -0.5983 & 0.0047 & & \\
Gender & 0.1121 & 0.0011 & & \\
Age & 0.0631 & 0.0002 & 0.0274 & 0.0019 \\
Age $^{2}$ & -0.0006 & 0.0000 & -0.0006 & 0.0000 \\
Education & 0.0871 & 0.0001 & 0.0043 & 0.0007 \\
Formal & 0.1811 & 0.0009 & 0.1143 & 0.0012 \\
Self Employed & 0.1025 & 0.0015 & 0.1842 & 0.0037 \\
Large Firm & 0.9960 & 0.0261 & 0.0303 & 0.0556 \\
Same Occupation & 0.0071 & 0.0008 & -0.0020 & 0.0008 \\
Same Sector & 0.0142 & 0.0009 & -0.0005 & 0.0009 \\
Crisis Dummy & -0.1630 & 0.0019 & -0.1509 & 0.0022 \\
Crisis $\times$ Formal & 0.0153 & 0.0018 & 0.0013 & 0.0021 \\
Crisis $\times$ Self Employed & -0.0534 & 0.0031 & 0.0617 & 0.0077 \\
Crisis $\times$ Large Firm & 0.0855 & 0.0639 & -0.2575 & 0.1362 \\
Crisis $\times$ Same Occ & 0.0251 & 0.0016 & 0.0337 & 0.0017 \\
Crisis $\times$ Same Sector & 0.0240 & 0.0020 & 0.0307 & 0.0020 \\
\hline$R^{2}$ & 0.3315 & & 0.0780 & \\
\hline \hline
\end{tabular}

Table 2 shows that the returns to tenure in occupation and sector are small in normal times. The coefficients on other variables all have their usual signs. Older, formal sector and self employed workers tend to have higher earnings than younger, informal wage workers. However, the situation changes dramatically during crises. Although average wages fall by about $15 \%$ during the crisis, the wages of individuals who do not change sectors or occupations are about $5 \%$ higher than wages of those who change both. A fixed effects estimation 
shows that, even correcting for individual heterogeneity, the returns to tenure in sectors and occupations increased sharply during the crisis to over $6.6 \%$. In other words, the reallocation of labor in the crisis was accompanied by a substantial fall in wages for individuals who changed sector and/or occupation.

\subsubsection{Semi parametric results}

To ensure that these results are not driven by changes in a few sectors or occupations, or by the parameterization of the wage equation, we also implement a semi-parametric matching estimator for sectoral and occupational change. The variable of interest is the change in real wages over the previous year and the matching is done on propensity scores. The latter are defined as the probability of treatment, where the treatment is a sectoral or occupational change. The control group consists of individuals who do not change sector or occupation in this period.

\section{Sectoral changes}

To estimate the returns to sectoral changes in normal and crisis periods, we construct two treatment and control groups. (1) T1: Individuals who change sector, but remain in the same occupation and C1: Individuals who do not change sector or occupation in the same period. The propensity score is estimated using a probit on individual and firm characteristics such as age, education, gender, self employment and formality status and firm size. (2) T2: Individuals who change sector and C2: Individuals who do not change sectors. The propensity score in this case takes into account changes in occupation by including a dummy for occupation change in the probit. Given these treatment and control groups we define the set of sectors

as $\mathcal{J}=\{1,2, \ldots j, k, \ldots J\}$ and $w_{i t}^{j}$ as the log wages of individual $i$ in sector $j$ at time $t$. Then the matching estimator is defined as

$$
\delta_{t+1}=\frac{1}{N_{T}} \sum_{i \in N_{T}}\left[\left(w_{i t+1}^{k}-w_{i t}^{j}\right)-\sum_{m \in N_{C}} \eta_{i m}\left(w_{m t+1}^{j}-w_{m t}^{j}\right)\right]
$$


In other words, we match each individual $i \in N_{T}$ who moved from sector $j$ to sector $k$ to a group of similar individuals from the control group who remained in sector $j$ in the same time period. The similar individuals are defined as those who have propensity score in an $\varepsilon$ neighborhood of the propensity score of the treatment. Defining $p_{i}$ as the propensity score for individual $i$,

$$
\begin{aligned}
\eta_{i m} & =0 \text { if }\left|p_{i}-p_{m}\right|>\varepsilon \\
& =\frac{\frac{1}{\left|p_{i}-p_{m}\right|}}{\sum_{\left\{i, m|| p_{i}-p_{m}<\varepsilon \mid\right\} \frac{1}{\left|p_{i}-p_{m}\right|}}}
\end{aligned}
$$

This means that members of the control group are weighted in inverse proportion to the distance between their propensity score and that of the individuals in the treatment group. As mentioned above, we control for occupational changes in two ways: either by selecting a sample where no occupational change takes place, either in the treatment or control group or by including occupational change in the propensity score.

It is important to emphasize that we make no claim as to the causality behind the estimation of the propensity score. The propensity score is defined as the probability that an individual is selected into treatment. In non experimental settings, it is hard to imagine that this probability is independent of the wage outcome. However, assuming additive heterogeneity, it is reasonable to assume that first difference of wages eliminates or at least mitigates the selection bias. The propensity score is therefore a convenient method for collapsing multi dimensional characteristics into one convenient index for ease of matching.

Table 3 presents the results of this estimation for the two groups with $\varepsilon=0.0001 .^{6}$ The results are quite unambiguous. In both groups, the drop in wages associated with moving sectors after the crisis is substantial, ranging from $11 \%$ to $13 \%$. In other words, individuals who moved sectors between 1994 and 1995 saw a substantial fall in their wages, compared to those who did not. This effect persists into 1996 and only dissipates by the subsequent year. In non crisis years, the effect is mixed, but rarely statistically significant. This seems

\footnotetext{
${ }^{6}$ Similar results obtain for $\varepsilon=0.001$. Results for the probit are available on request from the authors.
} 
Table 3: Semiparametric Results-Sector

\begin{tabular}{l|rl|rl}
\hline \hline & \multicolumn{2}{|c|}{ T1 and C1 } & \multicolumn{2}{|c}{ T2 and C2 } \\
& Coeff. & Std. Error & Coeff. & Std Error \\
\hline 1989.4 to 1990.4 & -0.0975 & 0.1363 & -0.0332 & 0.090 \\
1990.4 to 1991.4 & 0.1221 & 0.0856 & -0.0279 & 0.1116 \\
1991.4 to 1992.4 & & & & \\
1992.4 to 1993.4 & 0.0985 & 0.0567 & -0.0005 & 0.0325 \\
1993.4 to 1994.4 & -0.0451 & 0.0466 & 0.0496 & 0.0272 \\
1994.4 to 1995.4 & -0.1336 & 0.0644 & -0.1110 & 0.0416 \\
1995.4 to 1996.4 & -0.0626 & 0.0271 & -0.0386 & 0.0436 \\
1996.4 to 1997.4 & -0.0151 & 0.0105 & 0.0047 & 0.0367 \\
1997.4 to 1998.4 & -0.0651 & 0.0216 & -0.0250 & 0.0327 \\
1998.4 to 1999.4 & 0.0524 & 0.0315 & -0.0486 & 0.0218 \\
\hline \hline
\end{tabular}

reasonable since shifts across sectors and occupation can be initiated by either the employee or employer. The former are more likely to involve higher paying opportunities. In normal times inter sectoral or inter-occupational movements are likely a mix between voluntary and involuntary, and their net effect is indeterminate. In times of stress however, the proportion of involuntary moves is likely to be higher and is accompanied by a fall in wages. ${ }^{7}$

\section{Occupational changes}

A similar result holds for changes in occupation. Again, we define two treatment groups with corresponding control groups. The first treatment group is defined individuals who change occupation between period $t$ and $t+1$, but remain in the same sector. The control group is individuals who do not change occupation or sector. This pair of groups is referred to as $\mathrm{T} 1$ and $\mathrm{C} 1$ respectively. The second treatment group comprises of individuals who have changed occupation in the time period under consideration and the control group is individuals who remain in the same occupation and is denoted by T2 and C2. In this case,

\footnotetext{
${ }^{7}$ In our data it is not possible to distinguish between voluntary and involuntary movements among employed individuals. However, as showed in the previous section, there is a spike in involuntary unemployment in this period suggesting that many separations are involuntary.
} 
the probit includes a variable that takes represents sectoral change.

The matching estimator is defined in an analogous way

$$
\gamma_{t+1}=\frac{1}{N_{O}} \sum_{i=1}^{N_{O}}\left[\left(w_{i t+1}^{k}-w_{i t}^{j}\right)-\sum_{m \in N_{C}} \eta_{i m}\left(w_{m t+1}^{j}-w_{m t}^{j}\right)\right]
$$

where $k$ and $j$ now refer to changes in occupation, $N_{O}$ refers to the treatment group and $N_{C}$ to the control group. The weights $\eta$ are defined as in the previous subsection. Table 4 summarizes these estimators for the two groups.

Table 4: Semiparametric results - Occupation

\begin{tabular}{l|ll|ll}
\hline \hline & \multicolumn{2}{|l|}{ T1 and C1 } & \multicolumn{2}{l}{ T2 and C2 } \\
& Coeff. & Std. Error & Coeff. & Std Error \\
\hline 1989.4 to 1990.4 & 0.1723 & 0.1519 & -0.0458 & 0.0905 \\
1990.4 to 1991.4 & 0.0121 & 0.1430 & 0.0297 & 0.1049 \\
1991.4 to 1992.4 & & & & \\
1992.4 to 1993.4 & 0.0954 & 0.0703 & -0.0340 & 0.0524 \\
1993.4 to 1994.4 & 0.0256 & 0.0664 & 0.0340 & 0.0483 \\
1994.4 to 1995.4 & -0.1231 & 0.0525 & -0.0348 & 0.0180 \\
1995.4 to 1996.4 & -0.0881 & 0.0398 & -0.0557 & 0.0186 \\
1996.4 to 1997.4 & 0.0041 & 0.0208 & -0.0052 & 0.0022 \\
1997.4 to 1998.4 & 0.0210 & 0.0104 & -0.0055 & 0.0038 \\
1998.4 to 1999.4 & -0.0344 & 0.0298 & 0.0353 & 0.0346 \\
\hline \hline
\end{tabular}

The results of occupational mobility are similar to those for sectoral mobility. In normal times, the return is mixed, positive some years and negative for others, and estimated imprecisely. However, in the crisis years these returns are strongly negative, regardless of the treatment and control group used. Individuals who move occupations between 1994 and 1996 see a much larger fall in their wages than similar individuals who do stay in the same occupations in this period.

The above results demonstrate quite clearly that individuals who changed sector or occupation during the crisis experienced a larger fall in wages than individuals who did not. This 
differential wage loss is not present outside of this period.

\subsection{Financial crises and TFP}

While the crisis caused an acceleration in the reallocation of labor, it also triggered a massive drop in aggregate productivity, as we now document. As we also show in this section this phenomenon is not restricted to Mexico.

To measure aggregate TFP, we follow standard practice and assume that aggregate technological opportunities are well described by:

$$
\widehat{y}_{t}=z_{t} \widehat{k}_{t}^{\alpha} l_{t}^{1-\alpha}
$$

where $\widehat{y}_{t}$ and $\widehat{k}_{t}$ are detrended per capita output and capital, $l_{t}$ denotes hours worked per capita, and $z_{t}$ (detrended TFP) is a stationary process.

Measuring $z_{t}$ requires empirical counterparts for $\widehat{y}_{t}, \widehat{k}_{t}$ and $l_{t}$. As in Meza and Quintin (2007), we construct capital stock series using the perpetual inventory approach with geometric depreciation and yearly investment data from the International Financial Statistics (IFS) database (IMF, 2004). Like Bergoeing, Kehoe, Kehoe and Soto (2002) we measure real investment as the ratio of nominal gross fixed capital formation to nominal GDP multiplied by real GDP. We assume that capital depreciates at a yearly rate of $8 \%$. To set the initial capital stock, we follow Young (1995) and assume that the growth rate of investment in the first five years of the series is representative of the growth of investment in previous years.

For the labor input, we use total hours worked as measured in Bergoeing et al. (2002) for Mexico. ${ }^{8}$ For countries other than Mexico, an estimate of average hours worked is available for most sectors.

We calculate $\widehat{y}_{t}, \widehat{k}_{t}$, and $l_{t}$ by dividing aggregate real GDP, capital and hours by the number of adults between ages 15 and 64, detrending the resulting series for output and capital using

\footnotetext{
${ }^{8}$ We are currently computing a measure of total hours worked from our database to use in the calculation of TFP.
} 
the average geometric growth factor of GDP per worker in the period before the crisis episode. This factor is $1.0 \%$ for Argentina and 1.7\% for Mexico between 1960 and 1994, ${ }^{9}$ and 3.5\% for Indonesia, 5.3\% for South Korea, and 4.4\% for Thailand between 1960 and 1997. Finally, we set $\alpha=0.3$. Gollin (2002) finds that after distributing the income of the self-employed to capital and labor income, labor income shares do not vary much across countries and time, and take values in a fairly narrow interval around $70 \%$.

\footnotetext{
${ }^{9}$ In the case of Argentina, we use World Bank data to compute the trend growth rate between 1960 in 1994 since data from Kehoe (2003) only start in 1970.
} 


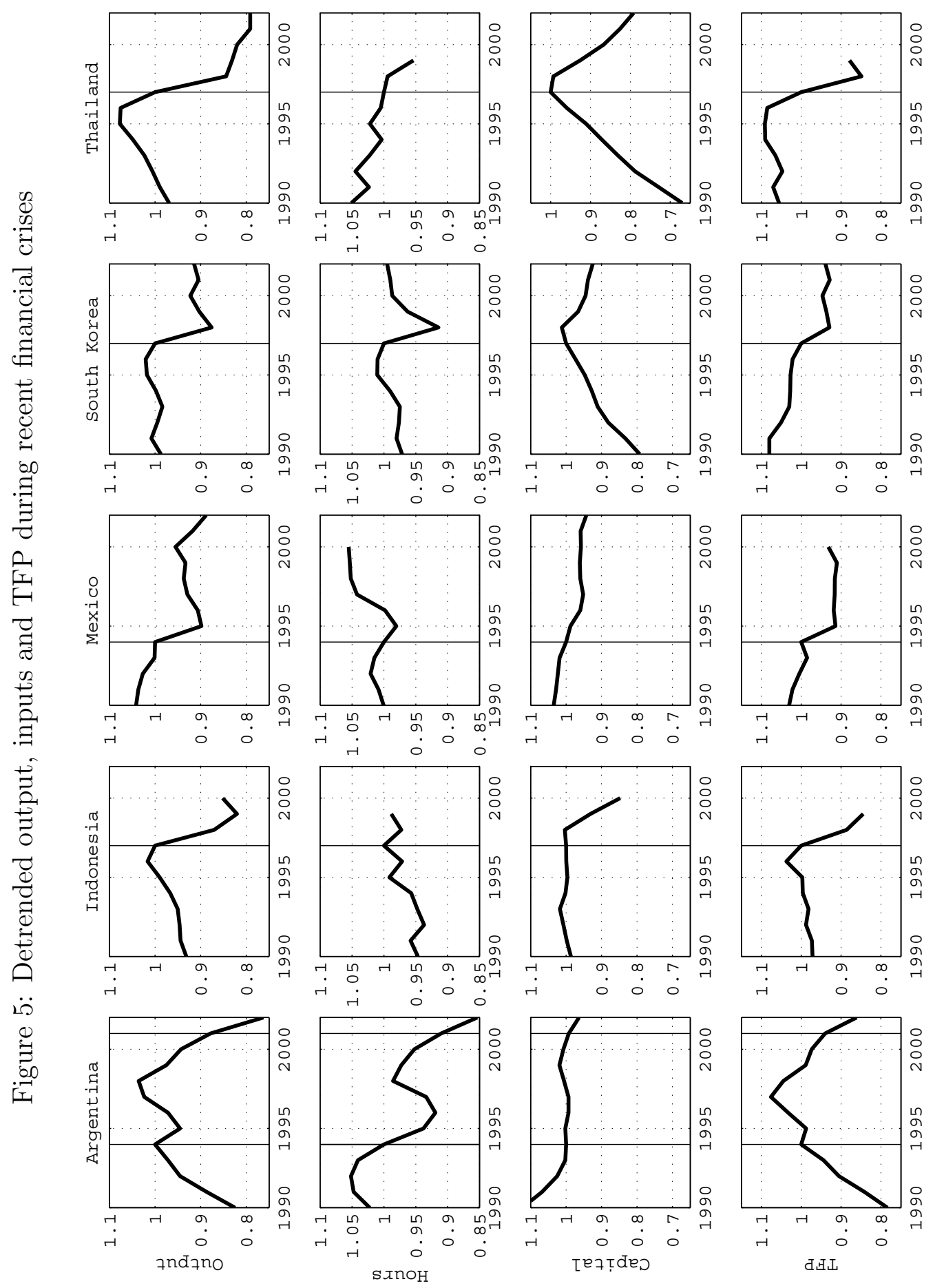


Figure 5 shows the resulting series for Argentina, Indonesia, Mexico, Thailand and South Korea with vertical lines marking the onset of each crisis. Each time series is scaled by its respective value at the onset of the crisis. Detrended output falls markedly in all cases. Capital, on the other hand, remains practically constant after the crisis, and hours fall less than output in all cases except for Argentina's Tequila crisis.

Since capital and labor fall relatively little during crises in most cases, TFP has to fall by a large amount to account for the fall in output: $7.9 \%$ in Argentina in 2002, $11.4 \%$ in Indonesia, $8.6 \%$ in Mexico, $15.1 \%$ in Thailand, and 7.1\% in South Korea. The magnitude of these falls is quite unusual for all countries. Argentina's response to the Tequila crisis in 1994 is somewhat of an exception, but notice that TFP was on a steeply upward trend before the crisis, and that it suddenly stopped growing in 1995.

Also notice that the falls in output and TFP triggered by crises tend to be persistent. They remain below trend in most cases for several years. ${ }^{10}$

What could explain this fall in TFP? Our hypothesis in this paper is that the reallocation of labor across sectors and occupations during the crisis destroyed specific human capital, leading to a decline in worker productivity, as evidenced by a fall in their wages. In the next section, we sketch out a model which captures the link between the two.

\section{Labor market turbulence and TFP}

In order to formalize and quantify the effects of labor market turbulence on productivity, this section describes an open economy, neoclassical model where the map from shocks to the worker productivity process to conventionally-measured TFP can be made explicit. We then simulate the effects of a shock to the productivity process consistent with the empirical evidence we presented in the previous section, and compare these effects to the relevant Mexican evidence.

\footnotetext{
${ }^{10}$ Cook and Devereux (2005) find that output remains persistently below trend in Asia after 1997, using a different detrending procedure. They report that in Malaysia, South Korea and Thailand, output remains below trend for at least 8 quarters.
} 


\subsection{A model of TFP}

Consider a discrete-time environment populated by a measure one of workers, and a representative firm. Workers are all endowed with a unit of time, which is supplied inelastically for labor.

Denote the quantity of effective labor that worker $i \in[0,1]$ can deliver to the firm at date $t$ by $x_{t}^{i}$. This effective labor supply evolves over time according to a Markov chain with finite support $X$ and transition probability function $\pi$. We also assume that a law of large number holds so that for all $\left(x, x^{\prime}\right) \in X^{2}$, the fraction $\pi\left(x, x^{\prime}\right)$ of workers of labor productivity $x$ at date $t$ see their productivity move to $x^{\prime}$ at date $t+1$.

To keep the dimension of the economy's state at date $t$ manageable, we adopt the representative family approach of Ljunqvist and Sargent (2007). Specifically, all workers belong to the same representative household that chooses a consumption plan $\left\{c_{t}^{i}: i \in[0,1], t \geq 0\right\}$ to maximize

$$
\int_{0}^{1}\left(\sum_{t=0}^{+\infty} \beta^{t} \frac{\left(c_{t}^{i}\right)^{\sigma}}{\sigma}\right) d i
$$

where $i$ labels the household's member in $[0,1]$ and $\sigma<1$.

The representative household has access to an international capital market where oneperiod risk-free claims earn exogenous return $r_{t}$ at date $t$. In this sense, we model Mexico as a small, open economy. We denote by $a_{t}$ the household's net holding of this asset at date $t$. To rule out Ponzi schemes, we assume that asset holdings are bounded below and that this exogenous bound is large enough in absolute value so as not to bind in equilibrium.

The household can also invest in physical capital, which it sells to firms at price $1+r_{t}^{k}$ at date $t$. Letting $k_{t}$ be the quantity of capital held by households in period $t$, we assume that adjusting capital across periods carries cost

$$
\frac{\psi}{2}\left(k_{t+1}-k_{t}\right)^{2}
$$


where $\psi>0 .^{11}$

In each period, the firm purchases capital from the household and hires workers of varying productivity. At date $t$ the firm operates with capital $K_{t}$ at date $t$ and with a measure $N_{t}$ of workers with productivity levels distributed according to $p_{t}$. It will soon become clear that in any equilibrium in this environment, the firm will always be willing to hire all available workers.

We assume that at any date a worker of productivity level $x \in X$ combined with a quantity $k$ of capital produces quantity $x^{1-\alpha} k^{\alpha}$ of the consumption good. We will think of worker together with some capital as a job. ${ }^{12}$ It follows that given input levels $N, K, p$ at a given date, the firm maximizes gross aggregate output by choosing a capital allocation $k: X \mapsto \mathbb{R}_{+}$to maximize:

$$
\sum_{x \in X} N p(x)\left[x^{1-\alpha} k(x)^{\alpha}\right]
$$

subject to

$$
\sum_{x \in X} N p(x) k(x)=K
$$

Clearly, it is optimal for the firm to equate the marginal product of capital across workers. Some algebra then implies that:

Proposition 3.1. Given aggregate capital $K>0$, aggregate labor $N$, and a distribution $p$ of productivity, gross aggregate output is given by

$$
F(K, N, p)=\left(\sum_{x \in X} p(x) x\right)^{1-\alpha} K^{\alpha} N^{1-\alpha}
$$

Proof. Given our functional forms, equating marginal products across workers requires that $k(x)=x k(1)$ for all $x \in X$. Feasibility then implies that $k(1)=\frac{K}{N \sum_{x \in X} p(x) x}$. Plugging this

\footnotetext{
${ }^{11}$ As is well-known, adjustment costs are necessary in open economy models to prevent investment from being counterfactually volatile. Assuming that adjustment costs are borne by households rather than firms is immaterial. An equivalent decentralization would have firms make investment decisions and bear adjustment costs. The specification we use shortens the exposition by keeping the firm's problem static.

${ }^{12}$ Ljunqvist and Sargent (2007) think of the same pair as a firm.
} 
information into the objective shows maximized aggregate output to be:

$$
\begin{aligned}
\sum_{x \in X} N p(x)\left[x^{1-\alpha} k(x)^{\alpha}\right] & =\sum_{x \in X} N p(x)\left[x^{1-\alpha}(x k(1))^{\alpha}\right] \\
& =\left[N^{1-\alpha} K^{\alpha}\right] \times \frac{\sum_{x \in X} p(x) x}{\left(\sum_{x \in X} p(x) x\right)^{\alpha}} \\
& =\left(\sum_{x \in X} p(x) x\right)^{1-\alpha} K^{\alpha} N^{1-\alpha}
\end{aligned}
$$

as claimed.

Note that conventionally-measured TFP in this environment is $\frac{F(K, N, p)}{K^{\alpha} N^{1-\alpha}} \equiv\left(\sum_{x \in X} p(x) x\right)^{1-\alpha}$. A fall in the quality of labor triggered for instance by a spike in involuntary separations cause a drop in conventionally-measured TFP. Our goal in this paper is to quantify this source of variation in TFP.

With this aggregation result at hand, we can complete the description of the firm's problem. Let $w_{t}$ be the price of effective labor at date $t$. Our result above implies that it is only the total effective labor $N \sum_{x \in X} p(x) x$ that matters for the firm, so that a worker's pay must be proportional to his contribution to this aggregate. ${ }^{13}$ Given a rate $\delta$ of depreciation of physical capital, it follows that at date $t$ the firms chooses a capital level $K_{t}$ and a total effective labor level $L_{t}$ that solves ${ }^{14}$ :

$$
\max K_{t}^{\alpha} L_{t}^{1-\alpha}-K_{t}\left(\delta+r_{t}^{k}\right)-L_{t} w_{t}
$$

As usual, given constant returns to scale, this problem only pins down the capital-labor ratio at which the firm is willing to operate.

\footnotetext{
${ }^{13}$ Strictly speaking, this is true under the assumption that the firm does not offer insurance contracts to workers.

${ }^{14}$ Note that $1+r_{t}^{k}$ is the net price of physical capital. In other words, letting $R_{t}^{k}$ denote the gross rental rate at date $t, r_{t}^{k}=R_{t}^{k}-\delta$. Making depreciation explicitly part of the firm's problem makes discussing endogenous utilization (as we do later) easier.
} 
Given these pricing conventions, the household's budget constraint at date $t$ is given by:

$$
\int_{0}^{1} c_{t}^{i} d i+a_{t+1}+k_{t+1}=\int_{0}^{1} w_{t} x_{t}^{i} d i+k_{t}\left(1+r_{t}^{k}\right)-\frac{\psi}{2}\left(k_{t+1}-k_{t}\right)^{2}+a_{t}\left(1+r_{t}\right)
$$

Because we have assumed that the distribution of labor productivity obeys a law of large numbers, and because we assume for the time being that the household foresees all prices perfectly, the household problem involves no uncertainty. Therefore, the household simply chooses among affordable consumption profiles the one that maximizes $\int_{0}^{1}\left(\sum_{t=0}^{+\infty} \beta^{t} \frac{\left(c_{t}^{i}\right)^{\sigma}}{\sigma}\right) d i$. Standard arguments show that it is optimal for the household to equate consumption across household members at all dates so that we may write $c_{t}^{i} \equiv c_{t}$ for all $t$.

An equilibrium in this environment is prices $\left\{w_{t}, r_{t}^{k}\right\}_{t=0}^{+\infty}$, household decisions $\left\{a_{t}, k_{t}, c_{t}\right\}_{t=0}^{+\infty}$, and firm decisions $\left\{L_{t}, K_{t}\right\}_{t=0}^{+\infty}$ such that:

1. Given prices, $\left\{a_{t}, k_{t}\right\}_{t=0}^{+\infty}$ solves the household's problem;

2. Given prices, $\left(L_{t}, K_{t}\right)$ solves the firms's problem at date $t$ for all $t \geq 0$;

3. The market for capital clears at all dates: $k_{t}=K_{t}$ for all $t \geq 0$;

4. The market for labor clears at all dates: $L_{t}=\int x_{t}^{i} d i$ for all $t \geq 0$;

The evolution of the capital stock and output in equilibrium in this open economy environment is characterized by the following second order difference equation, for all $t \geq 0$ :

$$
1+r_{t+1}=\frac{1+\left(\alpha_{k} \frac{y_{t+1}}{k_{t+1}}-\delta\right)+\psi\left(k_{t+2}-k_{t+1}\right)}{1+\psi\left(k_{t+1}-k_{t}\right)}
$$

where $k_{t}$ is the capital stock and $y_{t}$ is gross output at date $t$. Given an initial level of the capital stock and a sequence of interest rates, this equation can be simulated using a shooting $\operatorname{algorithm.~}^{15}$

${ }^{15}$ For computational details, see the computational appendix available at
http://www.dallasfed.org/research/vita/quintin/0704comp.pdf.


In the next section, we model turbulence as a shock to the worker productivity process and will calibrate this shock using data on the rise in worker movements during the Tequila crisis, and our estimates of the loss in earnings that follow these movements. We consider both the case where this shock is fully anticipated and the case where it comes to agents as a complete surprises at the onset of the crises and compute the predictions of the model for capital use, gross output and, most importantly given our purposes, conventionally-measured TFP.

We will also ask how making capital utilization endogenous affects the model's quantitative predictions. As mentioned earlier, financial crises create ideal conditions for large swings in capital utilization. For our purposes, endogenizing utilization seems particularly important. A sudden drop in the quality of labor, all else equal, causes the ratio of output to capital to fall, hence should cause utilization to fall as well. The endogenous response of utilization should therefore magnify the effect of the labor shock on TFP.

To make this formal, assume that the firm can alter the rate at which it utilizes the capital it allocates a particular worker. We assume that a worker of productivity $x \geq 0$ who operates with a quantity $k>0$ of capital at utilization level $u>0$ produces output $x^{1-\alpha}(u k)^{\alpha}$. Raising utilization thus raises a workers output, but as in Greenwood, Hercovitz and Huffman (1988), we assume that it also raises the quantity of capital lost to depreciation. Specifically, the depreciation rate is $\delta(u)=\frac{u^{\phi}}{\phi}$ where $\phi>1$. These new assumptions lead to a slightly altered version of our aggregation result:

Proposition 3.2. Assume that capital utilization is endogenous. Given aggregate capital $K>0$, aggregate labor $N>0$, and a distribution $p$ of productivity, gross aggregate output is given by

$$
F(K, N, p)=\left(\sum_{x \in X} p(x) x\right)^{1-\alpha}(u K)^{\alpha} N^{1-\alpha}
$$

where utilization solves:

$$
u=\left(\alpha \frac{F(K, N, p)}{K}\right)^{\frac{1}{\phi}}
$$


Proof. Utilization at the worker's level is a function of their output to capital ratio hence, of their marginal product of capital. As before, optimization on the part of the firm requires that this marginal product be equated across workers. Therefore, utilization must be the same across workers. The result then follows from manipulating first-order conditions and the same algebra as before.

This result implies that when capital utilization is endogenous, conventionally-measured TFP is $\frac{F(K, N, p)}{K^{\alpha} N^{1-\alpha}} \equiv u^{\alpha}\left(\sum_{x \in X} p(x) x\right)^{1-\alpha}$. Falls in the quality of labor now affect TFP not only directly but also via their effect on the capital-output ratio, hence on utilization. Simulating the resulting model amounts to simulating the same second-order difference equation as before, except that the ratio of capital to output now depends on optimal utilization choices as well. Details are in the computational appendix.

\section{Numerical simulations}

Equipped with these results, we can now simulate the effects of a shock to the worker productivity process consistent with the microeconomic evidence we presented in the empirical section.

To do so, we first need to find a data counterpart for the interest sequence we take as exogenous in the previous section. We will think of a period as one quarter. We calculate the interest rate $r_{t}$ during quarter $t$ as

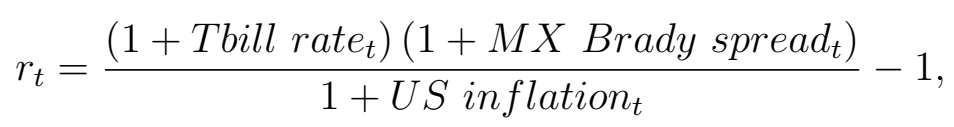

where Tbill rate $_{t}$ is the interest rate on US Treasury bills, MX Brady spread is $_{\text {s }}$ the spread between the return paid by (dollar-denominated) Mexican Brady bonds and the interest rate

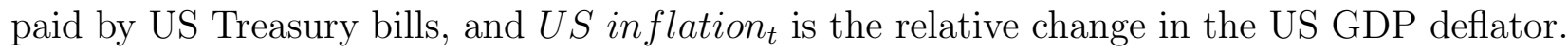
In other words, our proxy for $r_{t}$ is the real return paid by Mexican Brady bonds. ${ }^{16}$ Our

\footnotetext{
${ }^{16}$ Neumeyer and Perri (2005) use a similar construct to study the relationship between business cycles and
} 
sample of Mexican Brady bond data starts in the last quarter of 1990 and ends in the first quarter of 2003, and is shown on figure 1.

Next, parameters must be specified. We set the $\alpha$, the capital share, to 0.3 , a value in the middle of the range of estimates available in Gollin, 2002. We make $\delta=0.02$ which corresponds to yearly rate of depreciation of physical capital of $8 \%$. Preference parameters have no bearing in this version of the model on the behavior of capital, output and TFP. However, the equilibrium we compute assumes no asymptotic growth in any real variable. Such an equilibrium only exists in this environment provided we assume that $\beta \equiv \frac{1}{1+r}$ where $r$ is the long-run value of the interest rate. We choose the adjustment cost parameter to match the standard deviation of the investment to GDP ratio in Mexico prior to 1995 . We also choose the initial level of capital stock to match the capital-output ratio in Mexican data at the beginning of our sample. ${ }^{17}$

There only remains to specify the worker productivity process. Assume that the Markov chain's support is $X=\left\{1, x_{H}\right\}$ where $x_{H}>1$. In order to map our empirical findings into the model we outlined in the previous section, it is useful to decompose the specification of the Markov transition matrix that governs the evolution of worker productivity into two orthogonal subprocesses. First, all workers receive an idiosyncratic draw from a binary random variable $\sigma \in\{S, C\}$. We will interpret $\sigma=S$ as the event that the worker stays in the same sector and occupation, while $\sigma=C$ represents a sector or occupation change. Then, given $\sigma \in\{S, C\}$, worker productivity evolve according to matrix $\pi^{\sigma}$.

Since in our data $60 \%$ of workers change either sectors or occupation each year outside of the crisis period, we set the quarterly probability that $\sigma=S$ to 0.8 . Our data also suggest that the earnings of workers who stay put do not differ systematically from the earnings of workers who move. One way to generate this in our model is to assume that $\pi^{S}=\pi^{C}$.

We follow Ljunqvist and Sargent (2007) and assume that the productivity transition ma-

international interest rates in developing countries. We use end of quarter rates, using average rates does not alter our quantitative findings.

${ }^{17}$ The construction of all data counterparts to our model variables is described in detail in the appendix available at http://www.dallasfed.org/research/vita/quintin/0704comp.pdf. 
trix is symmetric during tranquil times. We then select $x_{H}$ so that, at the unique invariant symmetric distribution corresponding to this matrix (namely the distribution that puts equal mass on both types of workers, as a result of symmetry), the standard deviation of log worker productivity matches the standard deviation of the residual in quarterly Mincerian regressions with fixed effects specified as in the last column of table 2. This standard deviation is roughly 0.6 outside of 1995. The cross-terms of the transition matrix are selected to match the autocorrelation of this residual, namely 0.8. All told, outside the crisis, we set:

$$
\pi^{S}=\pi^{C}=\left[\begin{array}{ll}
0.9 & 0.1 \\
0.1 & 0.9
\end{array}\right]
$$

We model the change in the worker productivity process that occurs during the crisis as follows. Prior to the first quarter of 1995, the productivity distribution is at its invariant value. During each quarter of the crisis, our estimation results suggest that the yearly frequency of movements across sectors or occupations rises from 0.6 to 0.65 . Furthermore, average, conditional losses associated with those moves become significant at roughly $12 \%$. We decrease the likelihood that $\sigma=S$, accordingly, from 0.8 to 0.77 . We then assume that $\pi^{C}$ is replaced by $\tilde{\pi}^{C}$, which is defined by:

$$
\begin{aligned}
\tilde{\pi}^{C}(2,2) & =\omega \pi^{C}(2,2), \\
\text { while } \tilde{\pi}^{C}(1,2) & =\omega \pi^{C}(1,2)
\end{aligned}
$$

where $\omega \in(0,1)$ is such that average worker productivity in the event of a job loss are $12 \%$. The corresponding correction yields:

$$
\tilde{\pi}^{C}=\left[\begin{array}{ll}
0.936 & 0.064 \\
0.424 & 0.576
\end{array}\right] \text {. }
$$

Since we do not adjust the transition matrix for stayers, this will generate the desired earning 
gap between stayers and movers. Note, importantly, that even though the average productivity of workers does not fall according to this specification during the crisis, their earnings will fall because the wage rate does.

After 1995, $\pi^{C}$ governs the evolution of productivity for changers once again, and we let the distribution return to its invariant value over time at the rate inherent to our specification of the transition matrix.

Finally, we need to be explicit about agents' expectations. We will consider two scenarios. Under perfect foresight, we assume that agents know the entire sequence of interest rates, and wage rates. We also assume that they expect interest rates to remain constant at their last value in our sample for the indefinite future. This implies that the capital stock series converges in equilibrium to an invariant value and enables us to implement a shooting algorithm. In the second scenario, we assume that agents only foresee shocks up to the last quarter of 1994, but wrongly expect that thereafter interest rates will remain at their pre-crisis average and that there will be no change to the productivity process. Once the crisis strikes, agents immediately update their expectations to the true processes. We view this "perfect surprise" scenario as approximating a situation where agents perceive a financial crisis as a low probability event.

The result of the combined interest rate and worker productivity shocks under perfect foresight is shown in figure 6, under the assumption that capital utilization is exogenous. We normalize each statistic to be 1 in the last quarter of 1994 for ease of comparison. The first two panels of the figure describe the labor shock that we feed into the model. Average productivity falls by a cumulative 10\% during 1995 as the fraction of low productivity workers rises by $20 \%$, and both statistics then begin to slowly converge back towards their invariant value.

The model predicts - counterfactually - that the capital output ratio should have fallen before the crisis, as agents correctly foresee a period of high interest rates. This problematic feature will no longer emerge when we simulate a perfect surprise scenario. Capital utilization, by assumption, remains constant throughout our sample period. Output falls by roughly $7 \%$, 
inducing a symmetric response of the capital-output ratio. As we demonstrated in the previous section, standard neoclassical accounting would attribute the output fall to a corresponding fall in TFP. TFP, so measured, falls by a cumulative $7 \%$ in this first experiment. Note finally that the degree of persistence in the productivity process we have assumed produces a gradual return of TFP to its average value that is quite reasonable given the existing evidence.

Figure 6: Impact of turbulence, exogenous capital utilization
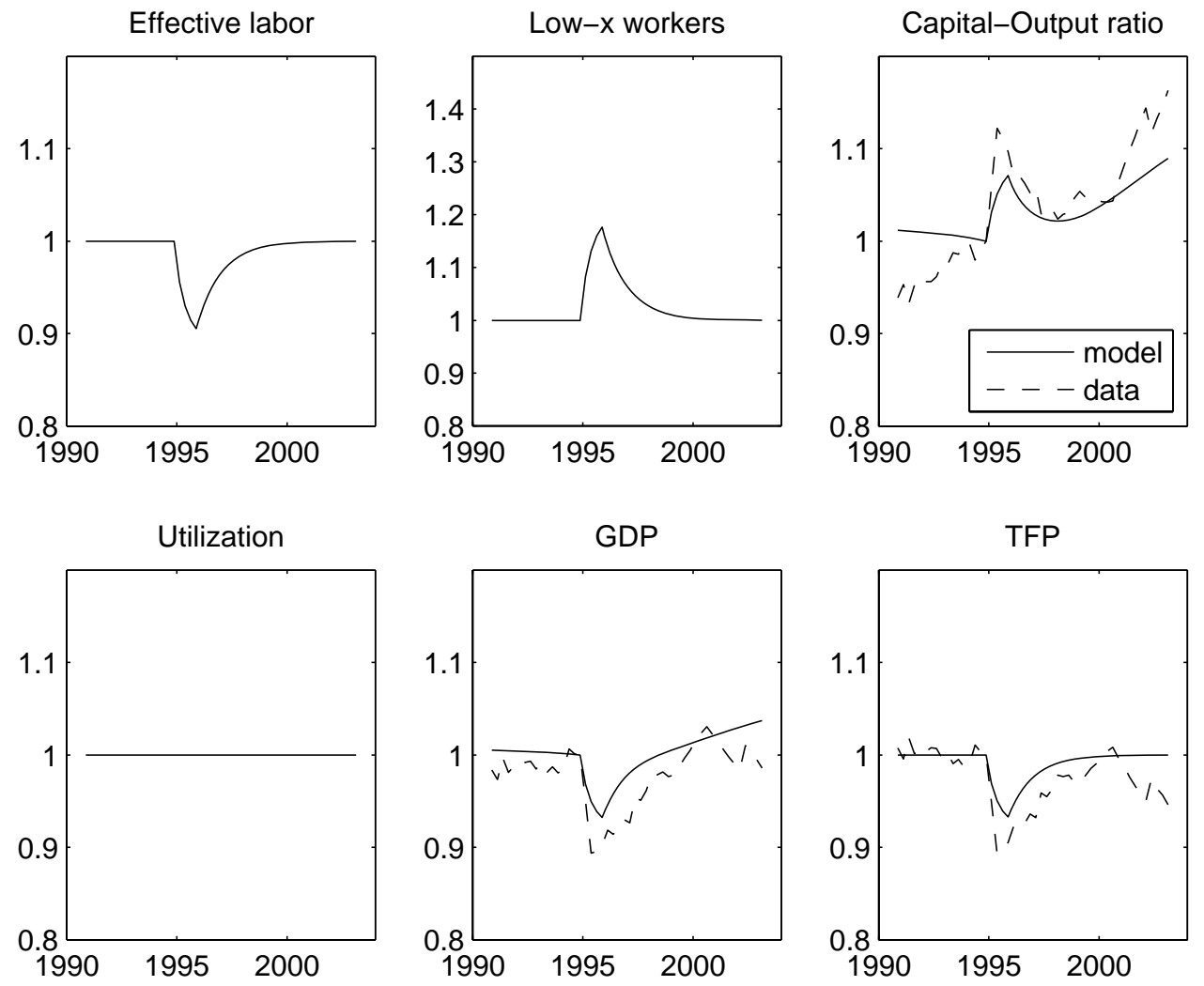

How much can capital utilization magnify this direct response? Figure 7 provides an answer by showing the predictions of a model with endogenous utilization where we assume that the curvature of the depreciation function is $\phi=1.46$, which given our other parameters yields a steady state depreciation rate of roughly $2.5 \%$, as before. The capital-output ratio 
continues to display a counterfactual decline before the crisis, and as tends to be the case with these models ${ }^{18}$ becomes highly volatile. Again, relaxing the perfect foresight assumption will address both issues, at least in part. Because the capital-output ratio spikes up when the crisis strikes, utilization now falls. As a result, output and TFP now fall by almost $9 \%$, which is very near what the data show.

Figure 7: Impact of turbulence, endogenous capital utilization
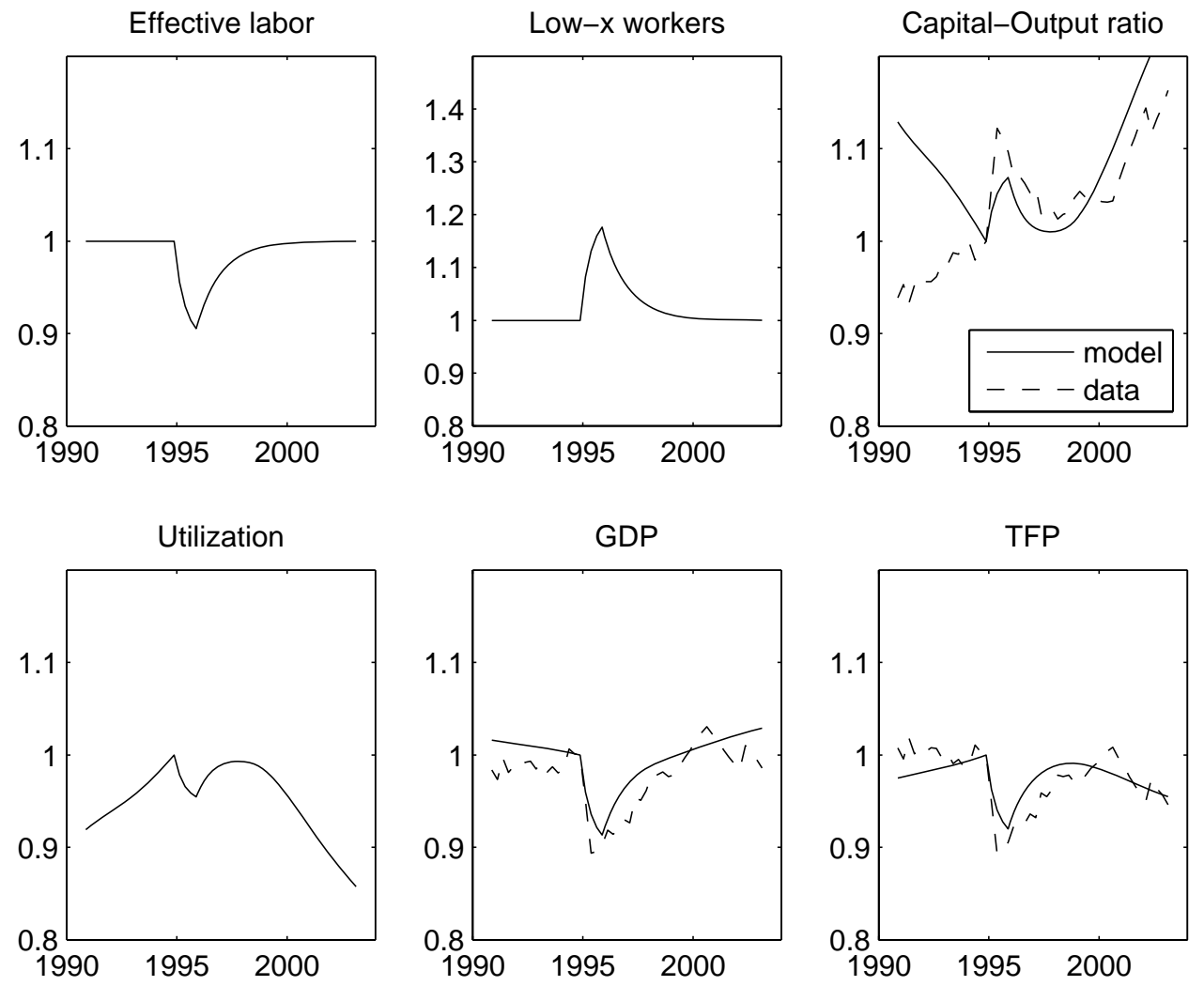

All told then, a drop in the quality of labor calibrated to match the empirical results we have produced in this paper, causes a cumulative fall in output and TFP in 1995 quite similar to their data counterparts. Human capital destruction could also account for the

\footnotetext{
${ }^{18}$ See Meza and Quintin, 2007, for a discussion.
} 
slow recovery of both statistics after the crisis. One discrepancy between our findings in the evidence is the fact the fall in GDP and TFP implied by our shock is monotonic until the end of 1995 while, in the data, both series reach their trough in the second quarter of 1995. This suggests that simulations where the effects of turbulence are concentrated in the first two quarters of 1995 will lead to improved results.

\section{Conclusion}

In this paper, we have presented direct evidence that during Mexico's 1995 financial crisis, workers whose employment sector or occupation changed experienced a much large fall in earnings than workers who stayed put. We have shown this finding to be robust to a host of econometric considerations. This suggests that the welfare consequences of financial turbulence are likely to be unevenly distributed, and concentrated among workers whose job is destroyed.

This finding also has constitutes a promising explanation for the collapse of conventionallymeasured total factor productivity that occurs during most crises. Labor market turbulence is likely to reduce average worker productivity by destroying accumulated experience and skills. We describe a simple model in which the mapping from worker productivity shocks to total factor productivity can be formalized. Numerical simulations of the model show that a shock to the individual worker productivity process calibrated to match the new empirical evidence we provide in this paper leads to a fall in TFP and subsequent recovery that closely resemble the relevant evidence.

This suggests that the labor market consequences of financial turmoil are large and significant, and could account for much of the real impact of crises. 


\section{References}

Bergoeing, R., P. J. Kehoe, T. J. Kehoe, and R. Soto (2002), "Decades Lost and Found: Mexico and Chile Since 1980", Federal Reserve Bank of Minneapolis Quarterly Review, Vol.26, pp. 3-30.

Burnside C., M. Eichenbaum, and S. Rebelo (2001), "Hedging and Financial Fragility in Fixed Exchange Rate Regimes", European Economic Review, Vol. 45, pp. 1151-1193.

Cavallo, M., K. Kisselev, F. Perri, and N. Roubini (2004), "Exchange rate overshooting and the costs of floating", New York University.

Chari, V. V., P. J. Kehoe, and E. R. McGrattan (2005), "Sudden Stops and Output Drops", American Economic Review, Vol. 95, pp.381-387.

Cook, D., and M. B. Devereux (2006), "Accounting for the East Asian Crisis: A Quantitative Model of Capital Outflows in Small Open Economies", Journal of Money, Credit and Banking, Vol. 38, pp. 721-749.

Corsetti, G., P. Pesenti, and N. Roubini (1999), "Paper Tigers? A Model of the Asian Crisis", European Economic Review, Vol. 43 , pp. 1211-1236.

Gertler, M. S. Gilchrist, and F. Natalucci (2007), "External Financial Constraints on Monetary Policy and the Financial Accelerator", Journal of Money, Credit and Banking, vol. 39, pp. 295-330.

Gollin, D. (2002), "Getting Income Shares Right", Journal of Political Economy, Vol. 110, pp. $458-474$.

Greenwood, J., Z. Hercowitz, and G. W. Huffman (1988), "Investment, Capacity Utilization and the Real Business Cycle", American Economic Review, Vol. 78, pp. 402-417.

Kambourov, G., and I. Manovskii (2007), "Occupational Specificity of Human Capital", International Economic Review forthcoming.

Kambourov, G. (2008), "Labor Market Regulations and the Sectoral Reallocation of Workers: The Case of Trade Reforms", Review of Economic Studies forthcoming.

Kehoe, T. J. (2003), "What Can We Learn from the Current Crisis in Argentina?", Scottish Journal of Political Economy, Vol. 50, pp. 609-633.

Lahiri, A., and C. A. Vegh (2007), "Output Costs, Currency Crises, and Interest Rate Defense of a Peg", Economic Journal, Vol. 117, pp. 216-239.

Ljungqvist, L. and T.J. Sargent (1998),, "The European Unemployment Dilemma", Journal of Political Economy, Vol.106, pp. 514-550. 
Ljungqvist, L. and T.J. Sargent (2007), "Understanding European Unemployment with a Representative Family Model", Journal of Monetary Economics, Vol. 54, 2180-2204.

Mendoza, E.G. (2002), "Credit, Prices, and Crashes: Business Cycles with a Sudden Stop", in S. Edwards and J. Frankel, editors, Preventing Currency Crises in Emerging Markets, NBER.

Mendoza, E.G. (2008), "Sudden Stops in a Business Cycle Model with Credit Constraints: A Fisherian Deflation of Tobin's Q", University of Maryland.

Meza, F. and E. Quintin (2007), "Factor Utilization and the Real Impact of Financial Crises", Advances in Macroeconomics, Vol. 7, Article 33.

Neumeyer, P. A., and F. Perri (2005), "Business Cycles in Emerging Economies: The Role of Interest Rates", Journal of Monetary Economics, Vol. 52, pp. 345-380.

Otsu, K., (2006), "A Neoclassical Analysis of the Korean Crisis", Bank of Japan, Institute for Monetary and Economic Studies Discussion Paper No 2006-E-26.

Pratap, S., and C. Urrutia (2008), "Financial Frictions and Total Factor Productivity: Accounting for the Real Effects of Financial Crises," ITAM working paper.

Young, A. (1995), "The Tyranny of Numbers: Confronting the Statistical Realities of the East Asian Growth Experience", Quarterly Journal of Economics, Vol. 110, pp. 641680 .

World Bank (2004), World Bank Development Indicators, CD database. 